\title{
AS CONTRIBUIÇÕES DA CATEGORIA DA TOTALIDADE PARA A ANÁLISE DOS MOVIMENTOS SOCIAIS
}

Gabriel Teles ${ }^{1}$

Resumo: Karl Marx foi o primeiro pensador a expressar a totalidade de forma dialética, ou seja, a partir das múltiplas determinações que é o concreto. A categoria da totalidade é a categoria fundamental no interior do método dialético, sendo o fio condutor para pensar os fenômenos sociais de forma ampla e que expressa a realidade. O presente artigo propõe discutir a questão da categoria da totalidade e sua possível contribuição analítica para as pesquisas que versam sobre os movimentos sociais, a partir dos escritos metodológicos de Marx e alguns de seus continuadores (Korsch, Lukács, Nildo Viana, etc.).

Palavras-chaves: Totalidade; Método Dialético; Karl Marx; Movimentos Sociais; Dialética Marxista.

\section{THE CONTRIBUTIONS OF THE TOTAL CATEGORY FOR THE ANALYSIS OF SOCIAL MOVEMENTS}

ABSTRACT: Karl Marx was the first thinker to express the totality dialectically, that is, from the multiple determinations that is concrete. The category of totality is the fundamental category within the dialectical method, being the thread to think social phenomena broadly and expressing reality. The present article proposes to discuss the question of the category of totality and its possible analytical contribution to the researches that deal with social movements, from the methodological writings of Marx and some of his followers (Korsch, Lukacs, Nildo Viana, etc.).

Key-words: Totality; Dialectic method; Karl Marx; Social movements; Dialectic Marxist.

\section{INTRODUÇÃO}

O tema dos movimentos sociais nas reflexões sociológicas tornou-se de grande importância e ganhou a atenção dos pesquisadores das ações sociais, sobretudo a partir da segunda metade do século XX. Tal importância se deu devido à própria força e organização dos movimentos sociais que começaram a criar uma expressiva notoriedade política, tanto nas

\footnotetext{
${ }^{1}$ Mestrando pelo Programa de Pós-Graduação de Sociologia UFG. Integra o conselho consultivo das revistas Espaço-Livre e revista Posição, além de integrar o conselho editorial da revista Enfrentamento. Contato: teles.gabriel@gmail.com
} 
instituições estatais quanto na sociedade civil, principalmente a partir da emergência do regime de acumulação conjugado ${ }^{2}$.

Como um fenômeno moderno, ou seja, constituído no interior da sociedade capitalista, os movimentos sociais expressam e são compostos a partir de uma base social que lhe constitui corpo e vitalidade: os grupos sociais (mulheres, negros, jovens, estudantes, ecologistas, sem-terra, sem-teto, etc.). Tais grupos, a partir de suas respectivas dinâmicas, provocam alterações tanto internas (no próprio movimento social), quanto externas (na totalidade da sociedade), cristalizando, portanto, seu papel mobilizador e político no conjunto das relações sociais erigidas no bojo do capitalismo.

Nessa lógica, os movimentos sociais fazem parte da paisagem contraditória da sociedade moderna efetivamente há quase um século, mas a reflexão sociológica sobre eles é relativamente recente. Segundo Maria da Glória Gohn:

\begin{abstract}
A temática dos movimentos sociais é uma área clássica de estudo da sociologia e da política, tendo lugar de destaque nas ciências sociais. Não se trata apenas de um momento da produção sociológica, como pensam alguns, confundindo a própria existência concreta do fenômeno e suas manifestações empíricas, seus ciclos de fluxos e refluxos, com a produção acadêmica sobre aqueles ciclos. Não se trata de um tema dos anos 60, 70 ou 80. Sem dúvidas, ganharam maior visibilidade a partir destas décadas, mas não são muito anteriores a elas, na vida real e na teoria (GOHN, 2004, p.329).
\end{abstract}

Deste modo, há uma relevante e volumosa bibliografia sobre os movimentos sociais, assentadas em diferentes concepções e abordagens. É por este motivo que não é possível afirmar que existe tão-somente uma abordagem homogênea sobre os movimentos sociais e/ou ao menos um significado consensual da própria expressão "movimentos sociais". Portanto, dependendo de qual perspectiva teórica/ideológica que se parta, é dada uma ênfase maior sobre uma ou outra parte específica do fenômeno dos movimentos sociais. Com raras exceções ocorre a análise deste fenômeno a partir da categoria da totalidade, uma das categorias do método dialético, observando suas múltiplas determinações. Por qual motivo ocorre esse processo? Seria o método dialético e sua categoria fundamental (a totalidade), imprecisas ou não adequadas para a análise dos movimentos sociais?

Nesse sentido, o presente texto tem como objetivo demonstrar as possíveis contribuições do método dialético, sobretudo a sua categoria fundamental, a totalidade, para a

\footnotetext{
${ }^{2}$ Sobre a conceito e a teoria dos regimes de acumulação ver o livro "O capitalismo na era da acumulação integral” (VIANA, 2009). Este regime de acumulação também é chamado de regime de acumulação fordista, por Harvey (1992).
} 
análise e pesquisas dos movimentos sociais. O método dialético foi desenvolvido por Karl Marx e alguns aspectos aprofundados pelos seus epígonos (Lukács, Labriola, Korsch, Kosik, Nildo Viana, entre outros).

Assim, em primeiro momento, realizaremos uma discussão sobre o pensamento de Marx e as possibilidades de encontrarmos contribuições para a análise dos movimentos sociais. E é exatamente na questão metodológica deste pensador que encontramos uma contribuição importante. Dessa forma, buscamos igualmente analisar o método dialético empreendido por Marx e pelo marxismo no geral, focalizando a questão da categoria totalidade, que integra este método. Assim, nossa última discussão se desagua nas formas como a categoria totalidade do método dialético pode contribuir na análise tanto teórica quanto concreta dos movimentos sociais. Este será o nosso itinerário.

\section{UMA CONTRIBUIÇÃO DE MARX PARA A ANÁlise DOS MOVIMENTOS SOCIAIS?}

Karl Marx é considerado um dos pensadores mais importantes desde a aurora da modernidade. Seus escritos e suas ideias ecoaram não apenas em seu tempo (metade do século XIX), mas ainda hoje sofre desdobramentos, desenvolvimentos e críticas. Tamanha influência pode ser medida em seu peso nas diversas formas de saberes que discutem o social: sociologia, história, economia, filosofia, etc., enfim, em uma diversidade de ciências e formas de saberes que resguardam as discussões teóricas do pensador alemão, sendo em algumas delas, tido como um clássico. Marx, no entanto, sempre foi crítico a todas essas formas de saberes, sobretudo as que acentuavam a divisão intelectual do trabalho, fragmentando a realidade e isolando suas determinações. Nesse sentido, Marx fez a crítica ao direito, crítica à filosofia, crítica à ciência, etc. A sua crítica, então, expressa aquilo que disse sobre a necessidade da crítica desapiedada do existente:

Embora a construção do futuro e sua consolidação definitiva não seja assunto nosso, é ainda mais claro, no presente, o que devemos realizar. Refiro-me à crítica desapiedada do existente, desapiedada tanto no sentido de não temer os próprios resultados quanto no sentido de que não se pode temer os conflitos com aqueles que detêm o poder. (MARX, 2008, p. 01).

Se um dos interesses fundamentais de Marx é contribuir para a transformação social, ou seja, para a construção de uma nova sociedade, então o existente, o presente, deve ser 
abolido. Se é certo que a consciência é o ser consciente (MARX \& ENGELS, 2007), então todas as formas de saberes ideológicas ${ }^{3}$, que fazem parte igualmente do presente e reproduzem o existente, devem ser criticadas de um ponto de vista revolucionário. É por isso que em Marx não há brechas para uma produção do saber e análise da realidade social de forma neutra, sem expressar os interesses de classe e valores, entre outras determinações, do pesquisador. Em outras palavras, a produção do saber faz parte das lutas de classes. É nesse sentido que Korsch irá afirmar que:

Para os eruditos burgueses dos nossos dias, o marxismo representa não só uma grave dificuldade teórica e prática de primeira ordem, mas, além disso, uma dificuldade teórica de segunda ordem, uma dificuldade "epistemológica". Não é possível arrumá-lo em nenhuma das gavetas tradicionais do sistema das ciências burguesas e mesmo se se quisesse abrir especialmente para ele e para os seus compadres mais chegados uma nova gaveta chamada sociologia, ele não ficaria sequer quieto lá dentro, iria constantemente passear para todas as outras. "Economia", "filosofia", "história", "teoria do Direito e do Estado", nenhuma destas rubricas pode contê-lo, mas nenhuma estaria a salvo dele se se quisesse metê-lo noutra (KORSCH, 1977, p. 137).

A produção intelectual de Marx traz ricas contribuições para se pensar tanto a humanidade de forma geral (a partir de suas discussões sobre natureza humana, modos de produção), a sociedade capitalista em específico (seus estudos sobre o modo de produção capitalista) e também na própria produção do saber dos fenômenos sociais (a sua teoria, materialismo histórico, e seu método, dialético). A sua reflexão, como colocamos anteriormente, visava a transformação social, e o agente social encarregado desta mudança é o proletariado. Nesse sentido, Marx via no movimento operário a possibilidade potencial de transformação devido a sua posição no conjunto das relações de produção capitalista. É por isso que sua produção intelectual estava engajada dentro do marco da luta dos trabalhadores. E é exatamente essa luta dos trabalhadores, no bojo de sua emancipação, que emancipa a humanidade no geral:

Na formação de uma classe com grilhões radicais, de uma classe da sociedade civil que não seja uma classe da sociedade civil, de um estamento que seja a dissolução de todos os estamentos, de uma esfera que possua um caráter universal mediante seus sofrimentos universais e que não reivindique nenhum direito particular porque contra ela não se comete uma injustiça particular, mas a injustiça por excelência, que já não possa exigir um título histórico, mas apenas o título humano, que não se encontre numa oposição unilateral às consequências, uma esfera, por fim, que não pode se emancipar sem se emancipar de todas as outras esferas da sociedade e, com

\footnotetext{
${ }^{3}$ Ideologia aqui entendida na própria definição de Marx e Engels (2007), ou seja, como falsa consciência sistematizada, um sistema de pensamento ilusório.
} 
isso, sem emancipar todas essas esferas - uma esfera que é, numa palavra, a perda total da humanidade e que, portanto, só pode ganhar a si mesmo opor um reganho total do homem. Tal dissolução da sociedade como um estamento particular, é o proletariado (MARX, 2013, p. 162).

Por esse motivo, Marx é considerado um humanista radical, observando que dentro da luta dos trabalhadores nasce a possibilidade da superação da sociedade de classe, o fim da pré-história humana e o nascimento da emancipação humana. Como podemos observar, Marx contribuiu não apenas intelectualmente para a transformação social, mas também politicamente - o que não deixa de ser também uma contribuição intelectual. Suas intervenções teóricas sempre rumavam a possibilidade concreta e prática da luta do movimento revolucionário do proletariado. Mas e os movimentos sociais no geral? Qual a posição de Marx sobre eles?

A primeira questão que devemos pontuar aqui é o tempo histórico onde Marx teve sua produção intelectual. Suas obras estão localizadas, temporalmente, no final da primeira metade do século XIX e se estende até a década de 80 desse mesmo século. Isto significa que seu pensamento, apesar de trazer vários elementos que possibilitem pensar o presente, possui limites de análise devido ao tempo histórico vivido por ele. Nesse sentido, já que, se concordarmos com um conjunto de autores que versam suas pesquisas sobre os movimentos sociais (JENSEN, 2014; GUNDER FRANK e FUENTES, 1989, VIANA 2016), os movimentos sociais apareceram, de forma já desenvolvida, só a partir da metade do século XX.

O que fica evidente aqui é que Marx não poderia refletir sobre os movimentos sociais já que eles só apareceram, de forma consolidada e desenvolvida, quase um século depois do período em que viveu. O máximo que se pode atestar é que, em sua época, os movimentos sociais começaram a se desenvolver de forma embrionária; tal como o movimento das mulheres (movimento feminino) e o movimento estudantil, mas ainda muito ligados aos movimentos de classe. É necessário esclarecer que movimentos sociais são diferentes dos movimentos de classe. Esta distinção é crucial, já que alguns autores colocam o movimento operário como um movimento social específico ${ }^{4}$. É Karl Jensen quem nos fornece a explicação sobre essa diferença:

Os movimentos sociais são diferentes dos movimentos políticos das classes sociais. Os movimentos sociais possuem como base grupos sociais e não classes sociais. A luta de classes gira em torno das relações de produção e as lutas dos movimentos

\footnotetext{
${ }^{4}$ Tal como as abordagens europeias e latino americana dos "novos movimentos sociais".
} 
sociais giram em torno de questões específicas relacionadas aos grupos sociais que lhe dão sustentação e só combatem diretamente as relações de produção quando surgem momentos históricos de acirramento das lutas de classes ou então quando um movimento social específico possui uma consciência revolucionária (com exceção daqueles movimentos que defendem tais relações) (JENSEN, 2014, p. 134).

Mas qual a relação entre os grupos sociais e as classes sociais? A dinâmica da sociedade capitalista é regida pela dinâmica das lutas de classes. Nesse sentido, os movimentos sociais, sendo seu arranjo social baseado em grupos sociais, possuem um vínculo substancial com a questão das classes sociais ${ }^{5}$ na sociedade capitalista. Isto significa dizer que a composição social dos movimentos sociais é, fundamentalmente, uma composição de classes. Os grupos sociais não são homogêneos; dentro de um mesmo grupo social, como o das mulheres, por exemplo, podemos ter diversas manifestações de classes ou subdivisões destas: mulheres burguesas, mulheres trabalhadoras, mulheres intelectuais, mulheres camponesas, etc.

[...] As classes sociais diferem dos grupos sociais que estão na base dos movimentos sociais porque são geradas social e historicamente (ao contrário dos grupos orgânicos) e possuir interesses comuns (o que nem sempre ocorre nos grupos sociais), além de que nem sempre tais grupos também efetivam lutas em comum contra outras classes (ou grupos). Contudo, o elemento fundamental é que a sua delimitação ocorre via divisão social do trabalho no sentido mais geral do termo. [...] As classes sociais são conjuntos de indivíduos submetidos à divisão social do trabalho na sociedade e é isso que gera um modo de vida comum, interesses comuns e luta comum contra outras classes sociais. Os grupos situacionais, que são os grupos sociais citados que mais podem ser confundidos com as classes sociais, são ou subdivisões destas ou produtos transitórios ou determinados por local de moradia, demandas sociais, situação social, etc. (VIANA, 2016, p. 52-53).

Marx, no máximo, fez alguns apontamentos sobre grupos sociais de sua época que, posteriormente, desenvolveram movimentos sociais. Este é o caso do grupo social das mulheres. Marx, ao analisar o material autobiográfico do francês Peucheut, descreve a situação social das mulheres daquela época, denunciando a especificidade do caráter opressivo que sofriam e a repressão sexual. Além disso, afirma o caráter destrutivo do capitalismo para além da exploração das classes trabalhadoras:

\footnotetext{
${ }^{5}$ Não se trata de pensar classes sociais a partir da ideologia da estratificação social (STAVENHAGEN, 1979) em que se cria modelos pré-fabricados a partir de renda (ou de qualquer outra "variante") e se aplica na realidade, sem vínculo nenhum com a realidade concreta. Compreendemos aqui classes sociais no sentido marxista, como um conjunto de indivíduos que possuem um determinado modo de vida, interesses e lutas em comum contra outras classes sociais a partir de uma determinada atividade estabelecida na divisão social do trabalho, derivada pelo modo de produção dominante (MARX, 1988; MARX, 1986; MARX e ENGELS, 2007; VIANA, 2012).
} 
Em alguns trechos sobre o "suicídio", extraídos das "mémoires tirés desenvolvimento archives de la police etc., par Jaques Peucheut", darei um exemplo dessa crítica francesa [...], que ao mesmo tempo pode nos mostrar até que ponto a pretensão dos cidadãos filantropos está fundamentada na ideia de que se trata apenas de dar aos proletários um pouco de pão e educação, como se somente os trabalhadores definhassem sob as atuais condições sociais, ao passe que, para o restante da sociedade, o mundo tal como existe fosse o melhor dos mundos (MARX, 2006, p. 22).

Como pudemos evidenciar, Marx não pensava que somente o proletariado sofria com as mazelas das consequências das relações capitalistas, apesar de ser o seu enfoque, devido ao seu papel revolucionário. Nesse sentido, podemos observar que Marx já prenunciava os conflitos em torno dos grupos sociais à medida que ia complexificando a sociedade e o desenvolvimento do modo de produção capitalista, mas não viveu o suficiente para presenciar o desenvolvimento dos movimentos sociais.

Feita a distinção fundamental entre movimento operário (e demais movimentos de classes) e os movimentos sociais, podemos avançar na discussão.

Já que Marx não escreveu sobre os movimentos sociais, suas contribuições se estruturam a partir de suas contribuições teórico-metodológicas. Como os movimentos sociais surgem, são produto e fazem parte da dinâmica da sociedade capitalista no geral, então é possível apontar contribuições da obra de Marx na análise dos movimentos sociais (VIANA, 2016b). O desenvolvimento da teoria da história das sociedades no geral (materialismo histórico) pode nos auxiliar a pensar a historicidade dos movimentos sociais que, assim como determinados fenômenos, surgem em determinadas condições histórica (Estado, classes sociais, etc.). Os movimentos sociais são um fenômeno específico da sociedade capitalista (e, especificamente, num determinado momento dele, já que não existem desde o seu início).

\footnotetext{
Para haver movimentos sociais é necessário que a divisão social do trabalho tenha se complexificado ao ponto de criar vários grupos sociais com interesses diferentes e o nível de desenvolvimento da consciência social esteja bastante elevado. Só existe um movimento social quando um grupo social realiza sua ação coletiva com uma regularidade e quando possui uma consciência coletiva. Essas pré-condições para a existência dos movimentos sociais só existem na sociedade capitalista. Por conseguinte, os movimentos sociais surgem com a sociedade capitalista e não existem nas sociedades pré-capitalistas (JENSEN, 2014, p. 134).
}

A teoria do capitalismo, desenvolvida de forma mais acabada em $O$ capital (MARX, 2013; 2014; 2017) também nos ajuda a pensar nas consequências da dinâmica e do desenvolvimento da acumulação de capital nos grupos sociais que, devido a suas respectivas 
condições e insatisfações sociais, unem-se e mobilizam, criando, assim, a possibilidade da emergência de determinados movimentos sociais. Determinadas ramificações do movimento ecológico surgem para combater as consequências desenfreadas da reprodução ampliada de capital, sobretudo em um de seus aspectos mais predatórios: a destruição ambiental, via poluição, superacumulo de lixo tóxico, etc. As lutas de classe na produção entre o proletariado e a burguesia, ponto essencial da dinâmica classista da sociedade atual, também traz consequências na hegemonia dos movimentos sociais. Enfim, uma multiplicidade de consequências na produção, circulação e reprodução do capital que estão inseridas na obra de Marx que versa sobre o capitalismo. Autores reconhecidos no campo dos estudos dos movimentos sociais assimilam, de forma coerente ou não, essa contribuição de Marx (LOJINE, 1981; BORJA, 1975; CASTELLS, 1988).

Outra contribuição de Marx para a análise dos movimentos sociais, e aqui encontrase o objeto de estudo do presente texto, é a questão metodológica. Marx elaborou o método dialético que ainda é uma ferramenta intelectual imprescindível para a análise da realidade. Apesar de não ter escrito uma obra sistemática sobre a sua base metodológica, é possível perceber, em sua obra, algumas discussões acerca da construção do método utilizado por ele. O próximo tópico pretende, brevemente, explorar e constituir, a partir dos escritos do próprio Marx, os aspectos metodológicos de obra e pensamento. À guisa de apoio, também utilizaremos alguns autores (Lukács, Korsch, Kosik e Nildo Viana) que contribuíram para o desenvolvimento e aprofundamento de algumas categorias do método dialético.

\section{ESCRITOS METODOLÓGICOS EM MARX}

O método, em qualquer forma de saber humano sistemático, possui um valor fundamental para a análise de qualquer fenômeno (seja ele físico, químico, social, etc.). Por este ângulo, é imprescindível que qualquer base teórica tenha, como pano de fundo, uma matriz metodológica. Isto significa dizer que há uma unidade entre teoria e método de pesquisa. No pensamento de Marx, não é diferente. O materialismo histórico é a aplicação de seu método na história humana. E esse método é o método dialético. Cabe dizer também, para não cair em um mero formalismo, que o método dialético está entrelaçado com a sua teoria da consciência. Ou seja, a questão aqui é saber como chegar ao real e se é possível acessá-lo via ferramentas intelectuais.

Hegel dizia que um determinado método é uma ferramenta subjetiva para se relacionar com o "objeto" (apud KOPNIN, 1978). Marx, inspirado em Hegel, mas invertendo 
o seu aspecto idealista/metafísico, coloca que a reconstituição da realidade concreta na consciência ocorre de forma distinta da forma como ocorre na realidade concreta em si (MARX, 1983). Por esse ângulo, o método seria um recurso heurístico (KORSCH, 1977) para efetivar a reconstituição mental da realidade. É, enfim, um mediador, entre a consciência e a realidade concreta (apesar da consciência igualmente também fazer parte dessa realidade, já que a consciência não é nada mais que o ser consciente segundo Marx).

O método dialético de Marx pode ser encontrado, de forma explícita, em alguns de seus escritos: no capítulo Método da Economia Política do livro Contribuição à Crítica da Economia Política (MARX, 2008), A Miséria da Filosofia (MARX, 2001), a Carta a Annenkov (MARX, 2001) e o Prefácio à Primeira Edição de o Capital (MARX, 2013), assim como no Prefácio à Segunda Edição (MARX, 2013). Em toda obra de Marx podemos notar a utilização do método dialético, mesmo que de forma ainda embrionária ou faltando alguns elementos que posteriormente são incorporados. Mas é na obra $O$ Capital (2013) que o método dialético é aplicado de forma rigorosa e coesa, apesar de ser um texto incompleto devido à morte do autor.

Marx, no primeiro prefácio de O Capital (2013), coloca que o principal instrumento de seu método é a abstração: “[...] na análise das formas econômicas não podemos nos servir de microscópio nem de reagentes químicos. A força da abstração [Abstraktionskaft] deve substituir-se a ambos" (MARX, 2013, p. 78). Aqui o autor coloca que como os fenômenos da natureza são diferentes dos fenômenos sociais é necessário utilizar outros instrumentos. A abstração é o instrumento fundamental da análise da realidade social. Marx explica o que entende por abstração no texto O Método da Economia Política:

Parece mais correto começar pelo que há de concreto e real nos dados; assim, pois, na economia, pela população, que é a base e sujeito de todo o ato social da produção. Todavia, bem analisado, esse método seria falso. A população é uma abstração se deixo de lado as classes que a compõem. Essas classes são, por sua vez, uma palavra sem sentido se ignoro os elementos sobre os quais repousam, por exemplo: trabalho assalariado, o capital etc. Esses supõem a troca, a divisão social do trabalho assalariado, o capital etc. O capital, por exemplo, não é nada sem trabalho assalariado, sem valor, dinheiro, preços etc. Se começasse, portanto, pela população, elaboraria uma representação caótica do todo e, por meio de uma determinação mais estrita, chegaria analiticamente, cada vez mais, a conceitos mais simples; do concreto representado chegaria a abstrações cada vez mais tênues, até alcançar as determinações mais simples. Chegado a esse ponto, teria que voltar a fazer a viagem de modo inverso, até dar de novo com a população, mas dessa vez não como uma representação caótica de um todo, porém como uma rica totalidade de determinações e relações diversas. O primeiro constitui o caminho que foi historicamente seguido pelo nascente Economia Política. Os economistas do século 17, por exemplo, começam sempre pelo todo vivo: a população, a nação, o Estado, vários Estados etc.; mas terminam sempre por descobrir por meio da análise certo 
número de relações gerais abstratas que são determinantes, tais como a divisão do trabalho, o dinheiro, o valor etc. Esses elementos isolados, uma vez que são mais ou menos fixados e abstraídos, dão origem aos sistemas econômicos, que se elevam do simples, tal como trabalho, divisão do trabalho, necessidade, valor de troca, até o Estado, a troca entre as nações e o marcado universal. O concreto é concreto porque é a síntese de muitas determinações, isto é, unidade do diverso. Por isso, o concreto aparece no pensamento como um processo da síntese, como resultado, não como ponto de partida, embora seja o verdadeiro ponto de partida e, portanto, o ponto de partida também da intuição e da representação. No primeiro método, a representação plena volatiliza-se na determinação abstrata; no segundo, as determinações abstratas conduzem à reprodução do concreto por meio do pensamento (MARX, 2008, p. 258-259 - itálicos nossos).

Neste trecho Marx expressa a questão do concreto-dado e do concreto-determinado. Ou seja, o ponto de partida é igualmente o ponto de chegada, que é a realidade concreta. Mas entre os dois pontos há a mediação do processo de abstração. É a partir desse processo que ocorre a reconstituição da realidade no pensamento que, a primeiro momento, vem a partir da intuição ou da representação sobre ela, ainda caótica ou a partir de representações ideológicas ${ }^{6}$. E logo após descobrir as múltiplas determinações que é o concreto, chega-se, então, ao concreto-determinado. O processo de abstração, então, possui algumas categorias que são recursos para chegar a análise dialética de qualquer fenômeno social. Categorias como abstração, determinação, concreto, totalidade, particularidade, fazem parte do método dialético, auxiliando na chegada da consciência correta da realidade (LUKÁCS, 1989). Para Marx, o método dialético é uma forma de não cair no canto da sereia da aparência do fenômeno, chegando a sua essência, ou seja, a sua determinação fundamental.

Não poderemos desenvolver a explicação de todas as categorias do método dialético, então focalizaremos aquela que é foco do presente texto: a totalidade. Mas antes é necessário colocar outro aspecto importante: o vínculo e a unidade entre o método dialético e a perspectiva do proletariado. Como colocamos anteriormente, Marx não parte de uma perspectiva neutra das ideias. Nesse sentido, para se chegar a verdade, é necessário partir da classe que tem a necessidade e possibilidade de transformar o mundo; que não há necessidade de esconder a exploração e dominação no mundo. Essa classe é o proletariado.

Passamos agora a análise da categoria da totalidade no método dialético desenvolvido por Marx.

\footnotetext{
${ }^{6}$ É necessário um esclarecimento complementar sobre partir das representações ideológicas. A ideologia, como falsa consciência sistematizada, inverte a realidade, mas há momentos de verdades, já que versa sobre a realidade e sua fundamentação precisa de um mínimo de estruturação e correspondência com essa realidade para possuir certa sustentação. Nesse sentido, para não começar do zero, ou seja, da instituição, já pode-se partir das
} 


\title{
A CATEGORIA DA TOTALIDADE NO MÉTODO DIALÉTICO
}

Todo método possui a formação de categorias do pensamento que são fundamentais para a compreensão da realidade. É o que diz o sociólogo Durkheim:

$\mathrm{Na}$ raiz de nossos julgamentos, há um certo número de noções essenciais que dominam toda a nossa vida intelectual; são aquelas que os filósofos, desde Aristóteles, chamam de categorias do entendimento: noções de tempo, de espaço, de gênero, de número, de causa, de substância, de personalidade, etc. Elas correspondem às propriedades mais universais das coisas. São como quadros sólidos que encerram o pensamento; este não parece poder libertar-se deles sem se destruir, pois tudo indica que não podemos pensar objetos que não estejam no tempo ou no espaço, que não sejam numeráveis, etc. As outras noções são contingentes e móveis; concebemos que possam faltar a um homem, a uma sociedade, a uma época, enquanto aquelas nos parecem quase inseparáveis do funcionamento normal do espírito. São como a ossatura da inteligência (DURKKHEIM, 1996, p. XV-XVI).

Cada método, circunscrito em seu marco teórico específico, possui um conjunto de categorias que fornece elementos para pensar o real. Este é o caso, por exemplo, do método compreensivo weberiano e suas categorias analíticas: tipo ideal, possibilidade objetiva, etc (WEBER, 2009); do método funcionalista, tal como as categorias de função, organismo, etc (DURKHEIM, 1996). O marxismo, a partir do método dialético, também possui suas categorias como colocamos anteriormente, sendo a totalidade uma das mais importantes e fundamental para a compreensão da teoria marxista, já que o próprio Marx compreende o concreto e a realidade como uma totalidade. Lukács, comentando sobre a possibilidade de explicação da história humana, ressalta a importância dessa categoria:

\begin{abstract}
O problema da compreensão unitária do processo histórico surge, necessariamente, como o estudo de todas as épocas e de todos os setores parciais, etc. E é aqui que se revela a importância decisiva da concepção dialética da totalidade, pois é muito possível que qualquer pessoa compreenda e descreva um acontecimento histórico de maneira essencialmente justa sem que por isso seja capaz de perceber este acontecimento no que ele realmente é, na sua função real no interior do todo histórico a que pertence. Isto é, de o perceber no interior da unidade do processo histórico (LUKÁCS, 1989, p. 27).
\end{abstract}

Quando se fala em totalidade, é necessário desmistificar algumas questões. Em primeiro lugar a totalidade não é o estudo de tudo que é real. Não é o exercício de esgotar todas as determinações, em seus mínimos detalhes e nuances. Totalidade é, 
fundamentalmente, a expressão que os fenômenos sociais, bem como seus desdobramentos, estão essencialmente relacionados uns aos outros e, que, portanto, não é possível pensar algum fenômeno ou determinação desse fenômeno de forma isolada:

\begin{abstract}
Existe uma diferença fundamental entre a opinião dos que consideram a realidade como totalidade concreta, isto é, como um todo estruturado em curso de desenvolvimento e de autocriação, e a posição dos que afirmam que o conhecimento humano pode ou não atingir a "totalidade" dos aspectos e dos fatos, isto é, das propriedades, das coisas, das relações e dos processos da realidade. No segundo caso, a realidade é entendia como o conjunto de todos os fatos. Como o conhecimento humano não pode jamais, por princípio, abranger todos os fatos - pois sempre é possível acrescentar fatos e aspectos ulteriores - a tese d a concreticidade ou da totalidade é considerada uma mística. Na realidade, totalidade não significa todos os fatos. Totalidade significa: realidade como um todo estruturado, dialético, no qual ou do qual um fato quaisquer classes de fatos, conjuntos de fatos) pode vir a ser racionalmente compreendido. Acumular todos os fatos não significa ainda conhecer a realidade; e todos os fatos reunidos em seu conjunto) não constituem, a totalidade (KOSIK, 1985, p. 35-36).
\end{abstract}

Em segundo lugar, a categoria da totalidade não é uma "invenção" de Marx. Ela foi pela primeira vez enunciada na filosofia de Spinoza (KOSIK, 1985) em sua discussão acerca da relação entre natura naturans e natura naturada. A sua elaboração foi determinante na polêmica da filosofia alemã de sua época quanto a distinção entre dialética e metafísica. Marx se inspira em Hegel, mas o que distingue a perspectiva de Marx é que ela se refere a realidade concreta, ao desenvolvimento da história dos seres humanos de carne e osso, e não ao desenvolvimento autônomo do espírito como pensava Hegel. Além disso, a perspectiva do proletariado torna-se imprescindível em todos os elementos do método dialético.

De acordo com Kosik (1985), existem quatro concepções distintas sobre a totalidade, cada qual respondendo a um princípio "epistemológico" correspondente. A primeira seria a concepção atomístico-racionalista, que vai de Descartes até Wittgenstein, concebendo o todo como totalidade dos elementos e dos fatos mais simples; a segunda e terceira, as concepções organicistas e organicístico-dinâmica, representados por Schelling, Spann, Durkheim, etc. colocando que o todo predomina sobre as partes; a quarta, enfim, a concepção dialética, que vai de Heráclito, passando por Hegel e tornando-se materialista em Marx, concebendo o real um todo estruturado que se desenvolve e se cria (no caso de Marx, se criando na história real e não da representação da mesma ou de seu “espírito").

E terceira e última colocação, a categoria da totalidade não pode ser utilizada igualmente de forma isolada; as outras categorias do método dialético não só ajudam na análise da realidade, mas como também são essenciais; o método é igualmente uma totalidade 
de categorias que são articuladas e aplicadas na pesquisa. Nesse sentido, quando Marx fala que o concreto é a síntese de múltiplas determinações, então aqui já demonstra que a categoria determinação tem uma relação direta com a totalidade, já que esta última é o conjunto articulado de várias determinações. Marx também fala que entre essas múltiplas determinações há uma que é sempre a fundamental; neste caso ele usa a palavra "lei”, mas no sentido hegeliano da palavra (como tendência) e não como lei objetiva, imutável, tal como usada nas ciências exatas (MARX, 2008). Nildo Viana nos dá um exemplo dessa questão utilizando a teoria da sociedade de Marx:

\begin{abstract}
A totalidade, para o materialismo histórico-dialético, é a sociedade. Mas toda totalidade é composta de partes. As partes que constituem a sociedade são o modo de produção dominante, os modos de produção subordinados e as formas de regularização das relações sociais. Tais partes, por sua vez, podem ser subdivididas em outras partes. Mas elas estão necessariamente ligadas uma à outra, formando uma totalidade. O que caracteriza a concepção marxista da totalidade é a ideia de que entre as partes que compõem o todo existe uma relação necessária e que o resultado desta relação entre as partes é a totalidade. Essas partes, desta forma, exercem "múltiplas determinações" sobre a totalidade, ou seja, sobre essas partes reunidas. Acontece que uma dessas partes exerce uma "determinação fundamental" sobre as outras, ou seja, sobre a totalidade. A própria totalidade é uma derivação desta parte fundamental (VIANA, 2007, p. 106).
\end{abstract}

Por esse ângulo, a sociedade é uma totalidade, que está inserida em outra totalidade que é a natureza, que por sua vez, inserida em outra totalidade que é o universo. Não podemos perder de vista esse princípio do método dialético, que já há desdobramentos para as outras categorias bem como para a análise concreta de qualquer fenômeno social. É necessário também dizer que quem produz a sociedade (ou qualquer outro fenômeno a ser estudado, como por exemplo, os movimentos sociais) são os seres humanos reais e concretos, de carne e osso; não há brecha aqui para pensar as categorias analíticas de forma idealista; e estas só são uma autêntica ferramenta analítica se está relacionado com a realidade, se servir a análise do concreto e, fundamentalmente, estiver partindo da perspectiva do proletariado.

Em síntese, qualquer fenômeno social deve ser entendido como uma totalidade. Utilizamos o exemplo da sociedade, mas, como um recurso heurístico (KORSCH, 1977), o método dialético permite analisar qualquer fenômeno que está relacionado ao social, a tudo que versa sobre o universo do ser humano (e suas associações durante a história). Nesse sentido, os movimentos sociais, como um fenômeno social, também podem ser compreendidos como uma totalidade e ser analisado a partir do método dialético. Faremos uma breve discussão acerca dessa relação no próximo tópico. 


\title{
MÉTODO DIALÉTICO, TOTALIDADE E MOVIMENTOS SOCIAIS
}

Como colocamos no início de nossa discussão, as análises que partem da totalidade concreta para explicar os movimentos sociais são bem raras, sobretudo no meio acadêmico. Isso se dá, por um lado, pelo aprofundamento da divisão intelectual do trabalho, criando uma hiper especialização do saber; e, por outro, fragmentando desse mesmo saber em ciências especiais, isolando a realidade e elegendo apenas uma parte para explicar o todo. Isso fica claro quando analisamos a literatura hegemônica dos estudos dos movimentos sociais.

Nesse sentido, há muito se fala sobre a concepção dos movimentos sociais (GOHN, 2002; GUNDER FRANK e FUENTES, 1989). Em nível sociológico, sua discussão se dá, sobretudo, a partir de seus objetivos (BOTTOMORE, 1970) ou a partir de elementos específicos, tais como sua dinâmica, confrontos (TARROW, 2009), sua capacidade de mobilização de recursos (OLSON apud GOHN, 2002), identidade coletiva (MELLUCI apud GOHN, 2002), consequências internas e/ou externas tendo em vista suas ações e, mais recentemente, pesquisas empíricas das últimas décadas (especialmente nas décadas de 80, 90 e início do século XXI), que acentuaram as dimensões culturais e transnacional do ativismo destes movimentos (ALONSO, 2009). Enfim, por uma multiplicidade de questões que permeiam as reflexões em torno deste fenômeno.

Não obstante, o seu grande problema teórico ainda se encontra na própria definição:

\begin{abstract}
O campo dos movimentos sociais é um dos mais indefiníveis que existe. Os movimentos são difíceis de definir conceitualmente e há várias abordagens que são difíceis de comparar. Os vários autores tentam isolar alguns aspectos empíricos dos fenômenos coletivos, mas como cada autor acentua elementos diferentes, dificilmente se pode comparar definições. Infelizmente estas são mais definições empíricas do que conceitos analíticos (MELUCCI, 1989: p. 55).
\end{abstract}

Além desse procedimento empiricista, isolando algumas de suas características e tornando-as como essência do fenômeno, há também os pesquisadores que contribuem para uma maior confusão acerca da própria delimitação do que seja movimento social, com definições tão amplas e abstratas que confundem outros fenômenos sociais em sua definição, tais como partidos políticos, manifestações, protestos e etc. (SCHERER-WARREN, 1989). A análise dialética dos movimentos sociais, diferentemente dos procedimentos demonstrados acima, parte não de algum aspecto isolado do mesmo, mas sim de sua totalidade. Há duas formas de abordar os movimentos sociais a partir do método dialético. 
O primeiro a própria construção conceitual de movimentos sociais de forma dialética. Há, portanto uma forma dialética de elaboração dos conceitos (VIANA, 2016b), que parte de uma determinada teoria da realidade e de uma determinada teoria da consciência. Os conceitos, para Marx, expressam a realidade.

\begin{abstract}
O objetivo é expressar a realidade tal como ela é, ou seja, o compromisso com a verdade é sua base intelectual e não com manipulação, estratagemas políticos, etc. Não se elabora um conceito para servir aos interesses de uma disputa política específica e sim tendo o fim geral da transformação radical e total das relações sociais, a emancipação humana, como objetivo. E esse processo é realizado através da percepção da realidade e necessidade de expressá-la, o que é realizado através do conceito. O conceito, que é um signo, é expressão da realidade, que é o significado. [...] Desta forma, na elaboração dialética do conceito se inicia pela necessidade de explicitar um significado e por isso esse processo começa pela distinção de qual aspecto da realidade se busca expressar. O significado é o ser, o aspecto da realidade, que o signo visa expressar e, portanto, é por este que se deve iniciar (VIANA, 2016b: p. 124-125).
\end{abstract}

Este procedimento é muito diferente das concepções racionalistas que criam modelos para posteriormente "inserir" a realidade nela, como o tipo ideal weberiano. Uma outra abordagem mais comum atualmente são as simplificações conceituais em meras definições empíricas sobre determinados fenômenos: toma-se como conceito uma manifestação concreta e específica de um movimento social determinado (movimento negro, por exemplo) e generaliza para os movimentos sociais em geral.

Devido ao espaço, não poderemos desenvolver quais autores discutiram e produziram um conceito de movimentos sociais a partir do método dialético, o que já fizemos em outro trabalho (TELES, 2017), mas podemos deixar alguns apontamentos. Devemos compreender os movimentos sociais a partir de sua base social que são os grupos sociais, onde tais movimentos provocam alterações tanto internas (no próprio grupo social) quanto no conjunto da sociedade (JENSEN, 1996). Nesse sentido, o movimento social só surge quando existe uma condição ou algo que os indivíduos que compõem um determinado grupo social têm em comum. A relação entre um grupo social e movimento social é bastante abstrusa, mas como bem lembra Karl Jensen (2014), já que marca uma nova fase deste grupo social, pois possibilita expressar um desenvolvimento da consciência e da experiência deste mesmo grupo. Portanto, em síntese, é necessário atentar-se que o que há de comum em todos os movimentos sociais é que todos eles possuem como fundamento um grupo social e estes geram alterações sociais e que estão inseridos numa totalidade maior que é a sociedade. 
A segunda forma de abordar os movimentos sociais numa perspectiva dialética - que pode ser um desdobramento da primeira, ou seja, após a elaboração dialética do conceito de movimentos sociais - faz-se necessário apreender suas determinações internas e articulá-las com as determinações da sociedade no geral. É impossível analisar os movimentos sociais sem relacioná-lo com o modo de produção capitalista, o Estado, a sociedade civil, a "indústria cultural" (capital comunicacional), etc. É nesse sentido que é preciso buscar qual o espaço dos movimentos sociais e seu significado dentro da dinâmica histórica na sociedade capitalista. Este procedimento de relacionar os movimentos sociais com outros fenômenos pode ocorrer a partir de um conceito que não esteja contemplado numa perspectiva dialética. Isso, sem dúvidas, traz problemas analíticos insuperáveis e intransponíveis. Este é o caso das análises de Castells $(1988 ; 1989)$ acerca dos movimentos sociais urbanos, demonstrando que a estrutura urbana, tal como o transporte, moradia, educação, etc. são afetados pela questão da reprodução da força de trabalho, o que remete as relações de produção dentro do modo de produção capitalista. Sua conceituação de movimentos sociais, no entanto, carece de uma base dialética de elaboração, já que ele compreende os movimentos sociais como sistemas de práticas sociais contraditórias, controvertendo a ordem estabelecida a partir das contradições específicas de uma determinada questão (a questão urbana, por exemplo).

\section{CONSIDERAÇÕES FINAIS}

O itinerário no presente texto demonstrou que o pensamento de Marx não só é válido para análise dos movimentos sociais, mas fundamental. Apesar de não ter vivido na época de sua emergência, Marx trouxe, para além de sua teoria da história, da teoria do capitalismo e da consciência, bases metodológicas que possibilitam uma consciência acertada acerca dos fenômenos dos movimentos sociais. A categoria totalidade assume importância fundamental nesse sentido. É a partir dela que podemos perceber, concretamente, as bases sociais, os objetivos e vínculos dos grupos sociais que dão origem e movimento a diversos conflitos estabelecido por grupos sociais. O que fizemos aqui foi tão-somente deixar algumas possibilidades de utilização do método dialético na análise e pesquisa dos movimentos sociais, sem pretensão de esgotar o debate que ainda está aberto.

\section{REFERÊNCIAS}


ALONSO, Angela. As teorias dos movimentos sociais: um balanço do debate. Lua Nova, São Paulo, 76: 49-86, 2009.

BORJA, Jordi. Movimientos sociales urbanos. Ediciones Siap - Planteos, 1975.

BOTTOMORE, Tom. Os Movimentos Sociais. In: Críticos da Sociedade: o pensamento radical na América do Norte. Rio de Janeiro, Zahar Editores, 1970.

CASTELLS, Manuel. Cidade, Democracia e Socialismo. 2a ed. Rio de Janeiro: Paz e Terra, 1988.

Movimientos Sociales Urbanos. México: Siglo XXI, 1988.

DURKHEIM, Emilie. As Formas Elementares da Vida Religiosa. São Paulo: Martins Fontes, 1996.

GOHN, Maria da Glória. M. G. M. Sociologia dos Movimentos Sociais. São Paulo: Cortez Editora. 2014. $2^{a}$ ed.

GUNDER FRANK, André e FUENTES, Marta. Dez teses acerca dos movimentos sociais. Lua Nova, 17, junho 1989, São Paulo, 1989: 19-48.

HARVEY, David. Condição Pós-Moderna. São Paulo, Edições Loyola, 1992.

JENSEN, Karl. Teses sobre os Movimentos Sociais. Revista Marxismo e Autogestão, Ano 01, N. 01, jan. /jul. 2014.

KOPNIN, P. V. A Dialética como lógica e teoria do conhecimento. Rio de Janeiro: Civilização Brasileira, 1978.

KORSCH, Karl. Marxismo e Filosofia. Porto: Afrontamento, 1977.

KOSIK, Karel. Dialética do Concreto. $4^{\circ}$ Edição, Rio de Janeiro: Paz e Terra, 1986.

LOJKINE, Jean. O Estado capitalista e a questão urbana. Tradução de Estela dos Santos Abreu. 2a . Ed. São Paulo: Martins Fontes, 1997.

LUKÁCS, G. História e Consciência de Classe. 2. ed. Rio de Janeiro: Elfos, 1989.

MARX, Karl e ENGELS, Friedrich. A Ideologia Alemã. São Paulo: Boitempo, 2007.

Manifesto do Partido Comunista. Petrópolis: Vozes, 1988.

MARX, Karl. Carta a Arnald Ruge. Carta dos Anais Franco-Alemães. Marxists Internet Archive, abril de 2008. Acesso em: https://www.marxists.org/espanol/m-e/cartas/m09-43.htm.

Crítica da filosofia do direito de Hegel. São Paulo: Boitempo, 2010.

Terra, 1986.

O Dezoito Brumário e Cartas A Kugelman. 5a Edição, Rio de Janeiro: Paz e 
. O Suicídio. São Paulo: Boitempo, 2006.

. O Capital. Livro I. São Paulo: Boitempo, 2013

O Capital. Livro II. São Paulo: Boitempo, 2014

. O Capital. Livro III. São Paulo: Boitempo, 2017

A Miséria da Filosofia. São Paulo: Centauro, 2001.

2008.

Contribuição à Crítica da Economia Política. São Paulo: Expressão Popular,

MELUCCI, Alberto. Um Objetivo para os Movimentos Sociais? Lua Nova, vol. 10, num. 17, jun. 1989

SCHERER-WARREN, Ilse. Movimentos Sociais. Ensaios de Interpretação Sociológica. $3^{\circ}$ edição, Florianópolis: Edufsc, 1989.

STAVENHAGEN, Rodolfo. Classes Sociais e Estratificação Social. In: MARTINS, José de Souza e FORACCHI, M. M. (Orgs.). Sociologia e Sociedade. RJ, LTC, 1978

TARROW, Sidney. O Poder em Movimento. Movimentos Sociais e Confronto Político. Petrópolis, Vozes, 2009.

TELES, Gabriel. Para uma análise marxista dos movimentos sociais: contribuições de Karl Jensen e Nildo Viana. Revista Despierta, Ano 04, n.04, 2017.

VIANA, Nildo. A Consciência da História. Ensaios sobre o Materialismo-HistóricoDialético. $2^{\circ}$ edição, Rio de Janeiro, Achiamé, 2007.

Os Movimentos Sociais. Curitiba: Editora Prismas, 2016.

A Contribuição de Marx para a Teoria dos Movimentos Sociais. Revista Despierta, Ano 03, Núm. 03, 2016b.

O capitalismo na era da acumulação integral. São Paulo: Ideias \& Letras, 2009.

WEBER, Max. Economia e Sociedade Vol I. Brasília: UNB, 2009. 